\title{
DETECÇÃO DE RESPOSTA SOROLÓGICA CONTRA MYCOPLASMA EM AVESDE CRIATÓRIOS DE “FUNDO DE QUINTAL" PRÓXIMOSA EXPLORAÇÕES COMERCIAIS DO ESTADO DE SÃO PAULO
}

\author{
F.G . Buchala', M .M. Ishizuka², L.A. M athias ${ }^{3}$, A. Berchieri Júnior ${ }^{3}$, \\ A.G .M. Castro ${ }^{4}$, A.L.S.P. Cardoso4, E.N .C. Tessari ${ }^{4}$, A .M .I. K anashiro ${ }^{4}$ \\ ${ }^{1}$ Coordenadoria de Defesa A gropecuária-CDA , A v. Brasil l, 2340, CEP 13073-001, Campinas, São Paulo, Brasil.
}

RESUMO

\begin{abstract}
Pesquisou-se anticorpos anti M ycoplasma gallisepticum (MG) e M ycoplasma synoviae (MS) nas populaçõesdeavesdeprodução nãotecnificadaecomfinal idadedesubsistência, em propriedades rurais em áreas geográficas próximas a granjas de reprodutoras (matrizeiros) do Estado de São Paulo. Foram selecionadas quinze criações vizinhas a 3 granjas de matrizes, consideradas livres de MG e MS. Soros sanguíneos de 406 gal inhas foram estudad os quanto a presença de anticorpos anti MG e MS. A avaliação foi realizada pela técnica de soroaglutinação rápida em placa. As freqüências depositividadeencontradas foram de $73 \%$ e $100 \%$ das aves aos antígenos deMG eMS, respectivamente. A s ocorrências observadas deaves sororreagentes foram de 30,3\% e 40,6\% para os antígenos de MG e MS, respectivamente. Os resultados indicaram que MG e MS estão amplamentedifundidosnas criações informais deaves de "fundo dequintal", colocando em risco constanteos criatórios deexploração industrial, osquai snecessitamadotar emanter boaspráticas de biossegurança para preservar a integridade sanitária dos plantéis.
\end{abstract}

PALAVRAS-CHAVE: Biossegurança, epidemiologia, infeccões, saúdedasaves, mi coplasmose.

\section{ABSTRACT}

DETECTION OF SOROLOGICAL RESPONSE AGAINST MYCOPLASMA IN DOMESTIC BACKYARD POULTRY AROUND COMERCIAL POULTRY FLOCKS IN THE STATE OF SÃO PAULO, BRAZIL. Thisinvestigation ai med to demonstratetheoccurrenceof serological reactions to $M$ ycoplasma gallisepticumandM ycoplasma synoviae in domestic backyard poultryfor self consumtion located nextto parentflocksin theStateof São Paulo. Fifteen backyard flocksaround 3parentflocks officially recognized asfreefrom MG and MSwereselected.Serafrom 406chickenswereresearched on antibodies anti MG and MS, by means of plate agglutination test. The frequencies found were $73 \%$ and $100 \%$ of flocks with chickens reacting to the antigens of MG and MS, respectively. The frequencies of reacting chickenswere $30.3 \%$ and $40.6 \%$ for theantigens of M G and MS, respectively. Theresultsshowed that theaetiological agentsstudied arewi despread among thebackyard flocks, posing a constant risk for the commercial poultry flocks, which need to adopt and keep good biosecurity practices to preservetheir sanitary status.

KEY WORDS: Biosecurity, epidemiology, infections, poultry heal ther, micoplasmoses.

\section{INTRODUÇÃO}

As infecções de aves por micoplasmas permanecem sendo as causas mais comuns de perdas na produção avícola (N ASCIMENTO, 1995), razão pela qual são contempladas pel o Programa N acional de Sanidade A vícola (PNSA). As empresas avícolas, matrizeiras e avozeiras (multiplicadoras genéticas) devem estar obrigatoriamente livres dessas enfermidades. Duas espécies são patogênicas para galinha, M ycoplasma gallisepticum (MG) eM ycoplasmasynoviae (MS) cujohabitatéo trato respiratório superior (JORDAN, 1981) e causam aerossaculite, com possibilidade de colonizar o trato reprodutivo defêmeas edemachos, comprometendo a fertilidade e a produção de ovos (JORDAN, 1975).

¿UniversidadedeSão Paulo, Faculdadede M edicina Veterinária eZootecnia, São Paulo, SP, Brasil.

¿U niversidadeEstadual Paulista, Facul dadedeCiências A gráriaseVeterinárias, Jaboticabal, SP, Brasil .

${ }^{4}$ Instituto Biologico, Centro A vançado dePesquisa Tecnológica do Agronegócio A vícola, Descal vado, SP, Brasil . 
O MG causa uma doença infecciosa denominada dedoençarespiratóriacrônica(DCR), commanifestação detosseedescargasnasaisnasgalinhasesinusite em perus. Infecções secundárias por Escherichia coli, principalmente, determinam um quadro de aerossaculiteemgalinhaseaerossaculite-sinusiteem perus. Quando o MG é introduzido no plantel, é rapidamentedisseminado para quase todas as aves, causando desenvolvimento da doença. N o invernoa doençarespiratóriaémaisfreqüenteemaisseveraem aves jovens, e nas adultas a manifestação está mais relacionada com a queda da postura. Ao lado do MS, o MG é um dos agentes mais disseminados em aves domésticas (Y ODERJUNIOR, 1997). A letalidadetotal por M G eM S observada na Califórnia, USA e com perus entre 1988 e 1989 foi de aproximadamente 9,0\%, 10,9\% para machos e 6,6\% para fêmeas (CHRISTIANSEN et al., 1996).

Surtos deMG foram estudados em granjas comerciais degalinhas eperus, everificou-sequea doença foi originária decriaçõesinformaisexistentesnavizinhança (LEy et al., 1993). A nticorpos contraM G foram detectados em 32 de 56 criações de fundo de quintal distantes uma mil ha degranjas comerciais (Mc BRIDE et al., 1991). Estudo de galinhas de fundo de quintal destinadasàsubsistênciafamiliar revel ou ocorrência de $33 \%$ de aves infectadas com M G e MS, indicando risco iminente para criações comerciais próximas (KelLy et al., 1994).

A via de transmissão mais importante é o ovo, o quetornaa doençaum fator delimitação do comércio internacional (LEVISOHN et al., 1985), além decontágio direto de ave a ave, contágio indireto (aerógena e fômites), alimentos e água contendo fezes e penas contaminadas (Y ODER JUNIOR, 1997).

A enfermidade causada por MS apresenta-sesob a forma subclínica que acomete preferencialmente sacos aéreos e usualmente associada à doença de $\mathrm{N}$ ew castle, bronquiteinfecciosaou ambas. Raramente apresenta-se sob forma sistêmica, que resulta em sinovite exsudativa, tendinite ou bursite. A sinovite infecciosa foi inicialmente observada em aves em crescimento, quatroa 12 semanas deidade, emregiões dealta densidadedeaves decorteno período de 1950 a 1960, nos USA . N as duas décadas quesesucederam, o aparecimento desinovitefoi decaindo, dandolugar à crescenteincidência de doença respiratória, a qual émais freqüentementeobservada em criações depostura comercial de múltiplas idades (Y ODER JUNIOR, 1997).

Em galinhas com sinais desinovite, a morbidade varia de 2 a $75 \%$, sendo mais freqüentea variação de 5 a $15 \%$, emesmo com a totalidade deaves infectadas a morbidade com sinais respiratórios é baixa, a letalidadenãoul trapassa $1 \%$. Emperus, a morbidade variaentrele20\%, al etalidadeéalta eacompanhada pelo canibalismo (Y ODERJUNIOR, 1997). Em granjas de perusdaCalifórnia, EUA, M Sfoi detectadoentre1988 a 1989, com letalidadede $9 \%$ (CHRISTIANSEN et al., 1996).

A aerossaculite éobservada em animais de qualquer idade e é causa de condenação de carcaças de frango decorteno matadouro (KING et al., 1973). FrangosqueadquiriramMSporviavertical parecemapresentar lesões de aerossaculite mais graves, e com maior freqüência ocorrem condenações.

$\mathrm{Na}$ cadeia de transmissão, as fontes de infecção são aves doentes, principal mente, seguidos deportadores ereservatórios (N ASCIMENTO, 2000). A transmissão é por contágio indireto, por meio de aerossóis, o que é facilmente demonstrado em lotes onde são colocadosal gunspintinhosjovensexperimentalmente infectados (Oıson et al., 1964). A disseminação, via de regra, é bastante rápida, atingindo todas as aves alojadasemum gal pão eraramenteéobservado comprometimento articular (WEINACK et al., 1983). Transmissão vertical ocorreem infecções naturaiseexperimentais (CARNAGHAN, 1961). A introdução de micoplasmas em plantéis comerciais é favorecida pelatransmissão vertical, enquanto a horizontal propicia a disseminação da doença (WHITHEAR, 1996).

O controle das micoplasmoses é essencial na avicultura industrial moderna. O monitoramento periódico assegura a manutenção da condição de granjas livres da infecção por MG e MS, evitando a transmissão para a progênie. Para o diagnóstico sorológico destas enfermidades existem antígenos comerciais disponíveis para o teste de soroaglutinação rápida(SAR) em placa, podendo-se obter reações cruzadas comM G, porém ostítulossão mais baixos e a reação é tardia (OLson et al., 1965). Sorologia por SA R, Inibição dahemaglutinação (HI) e Enzyme-Linked Immunosorbent Assay (ELISA) tem sido empregada para monitoria de granjas submetidas a programas de controle de MS em granjas comerciais demultiplicadoras eincubatórios (EwING et al., 1996).

\section{MATERIAL E MÉTODOS}

\section{A mostragem}

Foram selecionadas3granjas dematrizes(Filial 1, Filial 2eFilial 3), localizadasno Estado deSão Paulo, pertencentes a uma mesma empresa, integrantes do PNSA, com status sanitário oficial mentereconhecido como sendo livres de micoplasmoses, conforme de monstraram as colheitas de amostras seqüenciais durante os anos de 1998, 1999 e 2000.

Foram examinadas 15 criações vizinhas, sendo 7 , 5 e 3, respectivamente, localizadas ao redor dos matrizeiros: Filial 1, Filial 2 e Filial 3. 
Paraadeterminação daamostragem, faceàausência de informações acerca da prevalência de pelo menos uma das infecções em estudo, foram examinados 104 soros provenientes de aves caipiras de seis criações existentes nas vizinhanças de matrizei ros e foramobservados $57 \%$ e $10 \%$ deaves positivas frente ao antígeno testado, para MG eMS, respectivamente. Na Tabela 1 estão apresentados o número de amostrasobtidos decada criação, ea respectiva população no momento da amostragem em relação a cada matrizeiro.

Tabela 1 - Matrizeiros e respectivas criações vizinhas, segundo o número de aves e o número de amostras de soroestudadas deavesde"fundo dequintal",EstadodeSão Paulo, 2000.

\begin{tabular}{|c|c|c|c|}
\hline Matrizeiro & Criação & $\begin{array}{c}\text { № aves } \\
\text { existentes na } \\
\text { propriedade }\end{array}$ & $\begin{array}{c}\mathrm{N} N o \text { aves } \\
\text { examinadas }\end{array}$ \\
\hline & $1 \mathrm{~A}$ & 38 & 28 \\
\hline & $1 \mathrm{~B}$ & 60 & 39 \\
\hline & $1 \mathrm{C}$ & 47 & 33 \\
\hline Filial 1 & 1D & 48 & 34 \\
\hline \multirow[t]{6}{*}{ (360.000 aves) } & $1 \mathrm{E}$ & 34 & 26 \\
\hline & $1 \mathrm{~F}$ & 16 & 14 \\
\hline & $1 \mathrm{G}$ & 41 & 30 \\
\hline & Subtotal & 284 & 204 \\
\hline & $2 \mathrm{~A}$ & 15 & 13 \\
\hline & $2 \mathrm{~B}$ & 37 & 29 \\
\hline Filial 2 & $2 \mathrm{C}$ & 24 & 20 \\
\hline \multirow[t]{4}{*}{ (7.000 aves) } & 2D & 62 & 40 \\
\hline & $2 \mathrm{E}$ & 30 & 24 \\
\hline & Subtotal & 168 & 126 \\
\hline & $3 \mathrm{~A}$ & 30 & 24 \\
\hline Filial 3 & $3 B$ & 100 & 53 \\
\hline \multirow[t]{3}{*}{ (13.000 aves) } & $3 C$ & 25 & 20 \\
\hline & Subtotal & 155 & 97 \\
\hline & Total & 607 & 427 \\
\hline
\end{tabular}

\section{A mostras de sangue}

A colheita, o acondicionamento e a remessa das amostras desangue ao laboratório atenderam à Instrução N ormativa no 03 de 09/ 01/ 2002 (BraSIL, 2002), por tratar de controle de doenças do PNSA. A samostras foram processadas no Centro A vançado de Pesquisa Tecnológica do Agrone gócio A vícola do Instituto Biológico do Estado de São Paulo.

\section{Soroaglutinaçao rápida em placa para detecção de anticorpos contra M G e MS}

O procedimento seguiu as indicações do PNSA (BRASL, 1994). As amostras de soro foram inativadas em banho-maria a 560 C. Para os testes de soroaglutinação rápida em placa (SAR), utilizou-se antígeno comercial corado (Intervet International Boxmeer-Holanda). Foram homogeinizados $30 \mu \mathrm{L}$ de soro e $30 \mu \mathrm{L}$ deantígeno emplacas devidro, após $2 \mathrm{~min}$ verificou-sea formação degrumos indicando a reação antígeno-anticorpo. As amostras de soro bruto que apresentaram reação positiva foram diluídas em PBS nasproporções de1:5e1:10; erepetiu-seotestedeSAR. Segundo BRASL (1994), para fins de classificação inequívoca dos soros das aves pela prova deSAR, foram considerados positivos, para MG e MS, aqueles que apresentaram reação de aglutinação na diluição 1:10.

Parafins declassificação decriatórioscomavesde "fundo de quintal" sororreagentes ou não, considerou-se todo criatório que tivesse apresentado pelo menos uma ave com amostra positiva no exame sorológico ao antígeno correspondente.

Estimou-sea freqüência deocorrência (proporção) por intervalo deconfiança (IC), com 95\% deprobabilidade. Utilizou-se o teste da diferença entre duas proporções com aproximação normal (LESER et al., 1973).

\section{RESULTADOS}

Dos 15 criatórios de aves de "fundo de quintal" estudados, 11 apresentaram pelo menos uma ave sororreagente para o antígeno deMG, resultando em freqüência igual $73 \%$ dos criatórios com aves sorreagentes; a inferência por intervalo para $95 \%$ de confiança foi igual a LC (50,5\% I- - I 95,5\%).

Entre as 406 aves examinadas, 123 foram positivas à sorologia para MG, representando $30,3 \%$ de aves sororreagentes eum intervalo deconfiança para a inferência com $95 \%$ de confiança igual a LC (25,5\% I-_l 35,1\%). Os resultados observados, de acordo comaempresademultiplicaçãogenética (matrizeiro) e as propriedades com aves de "fundo de quintal" circunvizinhas, encontram-se na Tabela 2.

Todos os 15 criatórios deaves de "fundo dequintal" estudados apresentaram pelo menos uma ave sororreagente para o antígeno de MS, resultando em freqüência igual a $100 \%$ dos criatórios com aves sororreagentes.

A freqüênciadecriatórioscomavessororreagentes para o antígeno deMSfoi estatisticamentesuperior à freqüênciadecriatórioscomavessororreagentespara os antígenos de MG, quando avaliadas pelo teste estatístico da diferença entre duas proporções, com aproximação normal. 
Tabela 2 - Resultados positivos de sorologia para MG, segundo o matrizeiro e as respectivas criações deaves de "fundo dequintal", Estado de São Paulo, 2000.

\begin{tabular}{|c|c|c|c|c|}
\hline Matrizeiro & $\begin{array}{l}\text { Criação } \\
\text { "fundo de } \\
\text { quintal" }\end{array}$ & $\begin{array}{c}\mathrm{N} \text { o total } \\
\text { aves } \\
\text { examinadas }\end{array}$ & $\begin{array}{c}\mathrm{N} \text { o de } \\
\text { aves } \\
\text { positivas }\end{array}$ & $\begin{array}{c}\text { \%deaves } \\
\text { aves } \\
\text { positivas }\end{array}$ \\
\hline \multirow[t]{8}{*}{ Filial 1} & $1 \mathrm{~A}$ & 28 & 0 & 0,0 \\
\hline & $1 \mathrm{~B}$ & 39 & 0 & 0,0 \\
\hline & $1 \mathrm{C}$ & 33 & 7 & 21,2 \\
\hline & 1D & 34 & 30 & 88,2 \\
\hline & $1 \mathrm{E}$ & 26 & 11 & 42,3 \\
\hline & $1 \mathrm{~F}$ & 14 & 0 & 0,0 \\
\hline & $1 G$ & 30 & 0 & 0,0 \\
\hline & Subtotal & 204 & 48 & 23,5 \\
\hline \multirow[t]{6}{*}{ Filial 2} & $2 \mathrm{~A}$ & 13 & 7 & 53,8 \\
\hline & $2 \mathrm{~B}$ & 29 & 10 & 34,5 \\
\hline & $2 \mathrm{C}$ & 20 & 1 & 5,0 \\
\hline & $2 \mathrm{D}$ & 20 & 7 & 35,0 \\
\hline & $2 \mathrm{E}$ & 24 & 15 & 62,5 \\
\hline & Subtotal & 105 & 40 & 38,1 \\
\hline \multirow[t]{5}{*}{ Filial 3} & $3 A$ & 24 & 1 & 4,2 \\
\hline & $3 B$ & 53 & 33 & 62,3 \\
\hline & $3 C$ & 20 & 1 & 5,0 \\
\hline & Subtotal & 97 & 35 & 36,1 \\
\hline & Total & 406 & 123 & 30,3 \\
\hline
\end{tabular}

Entre as 406 aves examinadas, 165 foram positivasàsorologiaparaM S, representando $40,6 \%$ deaves sororreagentes, o que resultou em intervalo deconfiança para a inferência com $95 \%$ de confiança igual a LC (35,9\% I-_- 45,3\%).

Os resultadosobservados, segundo a empresa de multiplicaçãogenética (matrizeiro) easpropriedades com aves de "fundo de quintal" circunvizinhas, encontram-se na Tabela 3.

\section{DISCUSSÃO}

O conhecimento da epidemiologia de doenças transmissíveisédefundamental importânciaparafins dedelineamento deprogramasdesaúdeanimal (SIMON \& IsHIZUKA, 2000). Em qualquer estágio de evolução de um programa de monitoria sorológica, as fontes de infecção, representadas por animais silvestres e criações informais, são preocupações para as empresas avícolas. Estessão potenciaisreservatórios dedoenças e têm chamado a atenção de especialistas da área veterináriasobaóticaepidemiológica(THRUSFIELD, 1986; BERCHIERI JUNIOR, 1997), sendo necessária a realização de avaliações periódicas de toda a cadeia produtiva,
Tabela 3 - Resultados positivos de sorologia para MS, segundo o matrizei ro eas respectivas criações de aves de "fundo de quintal", Estado de São Paulo, 2000.

\begin{tabular}{|c|c|c|c|c|}
\hline Matrizeiro & $\begin{array}{l}\text { Criação } \\
\text { "fundo de } \\
\text { quintal" }\end{array}$ & $\begin{array}{c}\mathrm{N} \text { ototal } \\
\text { aves } \\
\text { examinadas }\end{array}$ & $\begin{array}{c}\mathrm{N} \text { o de } \\
\text { aves } \\
\text { positivas }\end{array}$ & $\begin{array}{c}\text { \% de } \\
\text { aves } \\
\text { positivas }\end{array}$ \\
\hline & $1 \mathrm{~A}$ & 28 & 2 & 7,1 \\
\hline & $1 B$ & 39 & 22 & 56,4 \\
\hline & $1 \mathrm{C}$ & 33 & 16 & 48,5 \\
\hline \multirow[t]{7}{*}{ Filial 1} & $1 D$ & 34 & 8 & 23,5 \\
\hline & $1 \mathrm{E}$ & 26 & 7 & 26,9 \\
\hline & $1 \mathrm{~F}$ & 14 & 1 & 7,1 \\
\hline & $1 G$ & 30 & 11 & 36,7 \\
\hline & Subtotal & 204 & 67 & 32,8 \\
\hline & $2 \mathrm{~A}$ & 12 & 8 & 66,7 \\
\hline & $2 B$ & 29 & 12 & 41,4 \\
\hline \multirow[t]{5}{*}{ Filial 2} & $2 \mathrm{C}$ & 20 & 11 & 55,0 \\
\hline & $2 \mathrm{D}$ & 20 & 18 & 90,0 \\
\hline & $2 \mathrm{E}$ & 24 & 17 & 85,0 \\
\hline & Subtotal & 105 & 66 & 62,9 \\
\hline & $3 A$ & 24 & 4 & 16,7 \\
\hline \multirow[t]{4}{*}{ Filial 3} & $3 B$ & 53 & 25 & 47,2 \\
\hline & $3 C$ & 20 & 3 & 15,0 \\
\hline & Subtotal & 97 & 32 & 33,0 \\
\hline & Total & 406 & 165 & 40,6 \\
\hline
\end{tabular}

com inclusão do estudo de fatores de risco para o contínuo aprimoramento dos programas de saúde animal (SCHLUNDT, 2001). Outro elo importante da cadeia epidemiológica éa via detransmissão, sendo que a el evada resistência dos agentes dessas doenças às condições do ambiente possibilita, a qual quer fômite, carreá-los para o interior dos estabel ecimentos de criação comercial, ultrapassando as barreiras da biossegurança instituídas (М Атsuмото et al., 2001).

O PNSA (BRASL, 1994) tem como objetivo diminuir a ocorrência de doenças como as micoplasmoses (MG e MS), importantes pelos elevados prejuízos que podemacarretarà exploração avícola(Y ODERJUNIOR., 1997).

A avaliação dapresençadefontes deinfecção pela detecção deanticorpos representa um rápido eprático instrumento de importância epidemiológica, por revelar contacto das aves com os respectivos agentes, demonstrando a presença ou a circulação deagentes etiológicos na população (WRAY \& DAVIES, 1994). Os levantamentossorológicostêmsidoempregadospara embasar os programasdecontroledemicoplasmoses (SATO, 1996).

O estudo da ocorrência de aves sororreagentes para cada agente estudado, entreas 406 aves pertencentes à amostra, revel ou respectivamentepara MG e 
MSosvaloreseseusinterval os deconfiança iguaisa $30,3 \%[$ IC $(25,5 \%|-| 35,1 \%)=95 \%]$ e $40,4 \%[I C(35,9 \%$ $|-| 45,3)=95 \%]$. O testeestatístico da diferença entre duas proporções demonstrou que a freqüência de aves sororreagentes foi maior para MS. Resultados obtidos no Zimbabwe mostraram que os patógenos MS eMG estavam igual mente presentes em 33\% das aves decriatórios de fundo quintal (Keltyet al., 1994); na Geórgia, EUA, o MG estava presente em 19,1\% e 40,0\% em duas espécies de aves de vida livre (LUTRELL et al.,2001), aproximando-sedosvaloresobtidosneste experimento.

Estudo epidemiológico realizado em criações de fundodequintal desubsistênciarevelou mortalidade degalinhas em decorrência de doença respiratória, e estudo sorológico em 420 aves de 52 criações revel ou $33 \%$ de animais com micoplasmoses por MS e MG (KelLy et al., 1994).

Estudos ecológicos com MG realizados nos EUA revelaram não somente a infectividade desse agente para aves de vida livre, bem como a relação direta entreo tamanho da população dessas aves e os valores deprevalência da micoplasmose em aves domésticas (H OCHACHKA \& DHONT, 2000). Carolina do Norte, EUA, surtos de $M G$ em galinhas e perus de granjas comerciaisforamoriginários decriações de "fundo de quintal" existentes na circunvizinhança (LEY et al., 1993). Essas observações, associadas às freqüências decriatórios com aves sororeagentes encontradas no presentetrabalho, indicam o risco deintrodução, em aves de exploração comercial, deagentes de doenças transmissíveis queseencontram distribuídos na natureza, infectando grande variedade deaves domésticas, disseminando-se nas aves de "fundo de quintal" na ausência de manifestação clínica, e que, pela multiplicidadedefatores detransmissão horizontal, podem romper asbarreirasdabiossegurançaeinfectar os lotes de aves de multiplicação genética (N ASCIMENTO, 1995; BERCHIERI JUNIOR, 1997).

\section{CONCLUSÕES}

Os resultados obtidos indicam que a elevada fre qüênciadecriatórioscomavessororreagenteseaelevada prevalência de aves sororreagentes aos antigenos testados, nospermiteconduir queosagentesestudados encontram-se distribuídos na natureza, infectando e disseminando-se nas aves de "fundo de quintal".

\section{REFERÊNCIAS}

BerChIERI JUnIoR, A. Doenças de transmissão vertical. In: Simpósio Técnico de Produção de Ovos, 7., 1997, Campinas, SP. A nais. São Paulo: 1997. p.133-142.
BraSIL. ProgramaN acional deSanidadeA vícola.Atoslegais. Portaria 193. Diário O ficial da República Federativa do Brasil, Brasilia,-DF,19deset.de1994. Poder Executivo.

BrasiL. N ormas Técnicas para Controle e Certificação de NúcleoseEstabelecimentos A vícol as como livres de Salmonella gallinarum eSalmonella pullorum elivres ou controladas para Salmonella enteritidis e Salmonella typhimurium. A tos legais. Instrução N ormativan 003. Diário 0 ficial da República Federativa do Brasil, BrasíliaDF, 09 de janeiro de 2002. Poder Executivo.

CARNAGHAN, R.B.A. Eggtransmission of infectioussynovitis. Journal of Comparative Pathology, v.71, p.279-285, 1961.

Christiansen, K.H.; HIRD, D.W.; Snipes, K.P.; Danaye-Elmi, C.; Palmer, C.W.; Mc Bride, M.D.; UtTerback, W.W. CaliforniaN ational A nimal HealthM onitoringSystem for meat turkey flocks 1988-89 pilot study: management practices, flock health, and production. A vian D iseases, v.40, n.2, p.278-284, 1996.

EWIng, m.l.; lauerman, I.h.; keven, s.h.; brown, m.b. Evaluation of diagnostic procedures to detect M ycoplasma synoviae in commercial multiplier-breeder farms and commercial hatcheries in Florida. A vian D iseases, v. 40, n.4, p.798-806, 1996.

HochachKa, W.M. \& Dhondt, A.A. Density-dependent decline of host abundance resulting from a new infectious disease. Proceedings of theN ational A cademy of Sciences of the U nited States of A merica, v.97, n.10, p.5303-5306, 2000.

JORDAN, F.T. Immunity to mycoplasma infections of the respiratory system in the domestic fowl and turkey. D evelopments in Biological Standartization, v.28, p.590596, 1975.

JORDAN, F.T. Mycoplasmosis in poultry. Israel Journal of M edical Sciences, v.17, n.7, p.540-547, 1981.

Kelly, P.J.; Chitauro, D.; Rohde, C.; Rukwava, J.; Majok, A.; DaVelaAR, F; M AsON , P.R. Diseasesand managementof backyard chicken flocksin Chitungwiza, Zimbabwe. A vian D iseases, v.38, n.2, p.626-629, 1994.

King, D.D.; KLeven, S.H.; Wenger, D.M.; Anderson, D.P. Field studies with M ycoplasma synoviae. A vian D iseases, v.17, p.722-726, 1973.

Leser, W., Ribeiro Netto, A.; Germek, O. A.; Marlet, J.M. Elementos deEstatística para a Ár rea de Ciências da Saúde. SãoPaulo:Escola Paulista deM MedicinadaUniversidadeFederal deSão Paulo, 1973. 180p.

LeVISOHN, S.; Glisson, J.R.; KLeVen, S.H. Ovo pathogenicity of $M$ ycoplasma gall isepticumstrainsin thepresenceand absence of maternal antibody. A vian Diseases, v.29, p.188-197, 1985.

Ley, D.H .;A VAKIAN , A.P.;BerkHoff, J.E. ClinicalM y coplasma gallisepticum infection in multiplier breeder and meat turkeys caused by F. strain: identification by sodium dodecyl sulfate-polyacrylamidegel el ectrophoresis, restriction endonucleaseanalysis, and thepolymerase chain reaction. A vian D iseases, v.37, n.3, p.854-862, 1993.

Lutrell, M.P.;Stallknetcht, D.E.; Kleven, S.H.;Kavanaugh, D.M.; CORN , J.L.; FISCHER, J.R. M ycoplasma gall isepticum in housefinches (Carpodacusmexicanus) and other wild birds associated with poultry production facilities. A vian D iseases, v.45, n.2, p.321-329, 2001. 
Matsumoto, A.; Miyama, M.; Murakami, S. Comparison of Salmonella isolation rates in different types of eggIayer hen housesin Chiba, Japan.A vian D iseases, v.45, n.1, p.195-200, 2001.

Mc Bride, M.D.; HiRd, D.W.; Carpenter, T.E.; SNiPes, K.P.; Danaye-Elmi, C.; Utterback, W.W. Health survey of backyard poultry and other avian species located withinonemileof commercial Californiameat-turkey flocks. A vian D iseases, v.35, n.2, p.403-407, 1991.

N Ascimento, E.R. Epidemiologiacomênfaseno diagnóstico epidemiológico em avicultura. Curso para médicos veterinários oficiais em Sanidade A vícola. Cuiabá, 1995.

N ascimento, E.R. Micoplasmoses. In:Berchieri Junior, A. \& MACARI , M. (Eds.). DoençasdasA ves. Campinas: Facta, 2000. p.217-224.

Olson, N.O.; Adler, H.E.; Damassa, A.J.; Corstvet, R.E. The effect of intranasal exposure to $M$ ycoplasma synoviae and infectious bronchitis on development of lesions and agglutinins. A vian D iseases, v.8, p.623-631, 1964.

Olson, N.O.; Yamamoto, R.; Ortmayer, H. Antigenic relationship between $M$ ycoplasma synoviae and $M$ ycoplasma gallisepticum. A merican Journal of $V$ eterinary R esearch, v.26, p.195-198, 1965.

SAto, S. A vian mycoplasmosisin A sia. R evueScientifiqueet Technique 0 ffice International des Epizooties, v.15, n.4, p.1555-1567, 1996.

SCHLUNDT, J. Emerging food-borne pathogens. Biomedical Environment Science, v.14, n.1-2, p.44-52, 2001.

SIMON , V.A. \& ISHIZUKA , M.M. Doença Infecciosa da Bolsa de Fabrício-DIB.In:BerCHIERI JunIOR,A.\&M ACARI,M.(Eds.). D oenças das A ves. Campinas: Facta, 2000. p.301-314.
Tajima, M.; Nunoya, T.; Yagihashi, T. An ultra structural study on the interaction ofM icoplasmagallisepticum with the chicken tracheal epithelium. A merican Journal of Veterinary Research, v.40, p.1009-1014, 1979.

Thrusfield, M.V. V eterinary epidemiology. London: Butterworths, 1986. 300p.

Weinack, O.M.; Snoyenbos, G.H.; Kleven, S.H. Strain of $M$ ycoplasma synoviae of low transmissibility. A vian Diseases, v.27, p.1151-1156, 1983.

WhitheAR, K.G. Control of avian mycoplasmosis by vaccination. Revue Scientifique et Technique 0 ffice International des Epizooties, v.15, n.4, p.1527-1553, 1996.

Wray, C. \& davies, R.H. Guidelines on detection and monitoring of salmonellainfected poultry flockswith particular referencetoSal monella enteritidis.In: Report of aWHO consultation on Strategies for Detection and Monitoring of Salmonella infected Poutry Flocks, Austria:WHO - Veterinary Public Heal th Unit, 1994. p.29-34.

YoderJunior, H.W. Mycoplasmosis. In:Calnek,B.W.;Barnes, H.J.; Beard, C.W.; Reid, W.M.; Yoder Junior, H.W. Diseases of poultry. A mes: I owaStateUniversity Press, 1997. p.197-235.

Recebido em 4/ 4/ 06 Aceito em 11/ 5/ 06 